\title{
The feasibility and satisfaction of an online global health education course at a single medical school: a retrospective study
}

\author{
Su-Jin Lee', Jayoung Park', Yoon Jung Lee', Sira Lee ${ }^{2}$, Woong-Han Kim ${ }^{1,3}$ and Hyun Bae Yoon ${ }^{1,4}$ \\ ${ }^{1}$ JW LEE Center for Global Medicine, Seoul National University College of Medicine, Seoul, Korea, ${ }^{2}$ London \\ School of Hygiene \& Tropical Medicine, London, UK, ${ }^{3}$ Department of Thoracic and Cardiovascular Surgery, Seoul \\ National University College of Medicine, and ${ }^{4}$ Office of Medical Education, Seoul National University College \\ of Medicine, Seoul, Korea
}

Purpose: The aim of this study was to evaluate the feasibility and satisfaction of an online global health education course for medical students in comparison with an in-person of the course and to assess students' preferences regarding online methods of delivery.

Methods: Second-year medical students enrolled in this course in 2019 (in-person) and 2020 (online). The attendance rate, satisfaction in the course evaluation survey, and academic achievement on the written final examination were utilized to compare the two different methods of course delivery. The medical students who took the online course were also asked about their preferences regarding the method of course delivery and the advantages and drawbacks of each method of online lectures.

Results: There was no significant difference in the attendance rate and overall satisfaction between the two groups. The mean score on the written examination of the online course $(84.1 \pm 19.6)$ showed comparable effects to the in-person course $(78.0 \pm 18.3)$. The percentages of students who achieved high performance $(55.5 \%)$ and the achieved minimum requirement $(95.9 \%)$ were also maintained compared to the in-person course (14.6\% and $93.6 \%$, respectively). Medical students preferred the online course to the in-person course; in particular, they preferred prerecorded videos over live streaming online lectures.

Conclusion: The participation, satisfaction, and the academic achievement of the online course were comparable to those of the in-person course. However, the greatest drawback of the online course was the lack of interaction between peer learners. Therefore, diverse methods for online education should be considered to increase students' sense of belonging to a learning community.

Key Words: Undergraduate medical education, Online education

\section{Introduction}

In the era of globalization, doctors need to have a broad knowledge of tropical diseases and global health issues, as well as expertise related to general medical practice [1]. Thus, professional education on global health and its related systems is becoming a priority in medical schools' curricula [2].

The Seoul National University College of Medicine started a global health education course in 2015 as part of the regular medicine curriculum to foster leadership,
Received: September 25, 2020 • Revised: November 9, 2020 • Accepted: November 16, 2020 Corresponding Author: Hyun Bae Yoon (https://orcid.org/0000-0003-4367-5350)

JW LEE Center for Global Medicine, Seoul National University College of Medicine, 71 Ihwajang-gil, Jongno-gu, Seoul 03087, Korea

Office of Medical Education, Seoul National University College of Medicine, 103 Daehak-ro, Jongno-gu, Seoul 03080, Korea

Tel: +82.2.740.8418 Fax: +82.2.745.6373 email: hbyoon@snu.ac.kr
Korean J Med Educ 2020 Dec; 32(4): 307-315.

https://doi.org/10.3946/kjme.2020.178

eISSN: 2005-7288

(C) The Korean Society of Medical Education. All rights reserved. This is an open-access article distributed under the terms of the Creative Commons Attribution Non-Commercial License (http:// creativecommons.org/licenses/by-nc/3.0/), which permits unrestricted non-commercial use, distribution, and reproduction in any medium, provided the original work is properly cited. 
future global perspectives, ethical awareness, and the spirit of service, thereby helping medical schools worldwide to adapt to the growing necessity of implementing such courses. The "Human-Society-Medicine" course, which includes a global health lecture, aims to enhance empathic understanding and expertise regarding communication, leadership, medical ethics, legal systems in global health, professionalism, and social obligations, which are essential competencies for medical professionals to develop during their studies [3].

This course is a required subject for the second year of medical school, and grades are given by calculating attendance rate, attitude to participate in small group discussion, and written test score.

In 2020, the Seoul National University College of Medicine implemented a change in its method of this course delivery through online education and e-learning, using various online platforms to reduce the risk of infection and to relieve the anxiety caused by in-person lectures on coronavirus disease 2019 (COVID-19) [4].

The spread of COVID-19 has made it necessary to develop and implement online lectures. The medical education has also prompted changes, as coursework was rapidly developed to be delivered through free online platforms using high-tech methods and online lectures, including key clinical conditions, case studies, and examination questions. These new methods are wellaccepted by medical students who can access the lectures easily, as lectures can be repeated as needed [5]. Medical schools have also promptly developed online lectures worldwide, using various online platforms such as Zoom [5]. Egypt's medical schools have implemented teambased learning using Zoom's breakout room function [5]. However, the spread of COVID-19 is not the only factor contributing to the introduction of online education in medical schools. In particular, the online learning is considered an effective pedagogical method for global health education due to its perceived interactivity and multimedia approach [6].

For efficient online education, several factors can be considered to promote the advancement of medical education through online global health instruction. For online education to ensure autonomous learning and to prevent gaps in individual learners' technological skills and various environments [7], software systems and learning structures that are more sophisticated and systematic than existing face-to-face education must be developed and established. In addition, reflection activities, learning attitudes, and motivation should be improved through the promotion of active interactions with peer learners on various online platforms [8].

However, insufficient comparative analyses have dealt with the feasibility and satisfaction of online courses, which are emerging as an alternative to in-person courses amid the COVID-19 pandemic and research that made suggestions for efficient online education. In particular, no studies have yet analyzed studies analyzing the participation, satisfaction, academic achievement, and preferences of medical students regarding global health coursework.

This study aimed to compare the levels of participation, satisfaction, academic achievement, and preferences of medical students who attended in-person and online courses on global health education at Seoul National University College of Medicine, and to analyze the advantages and drawbacks of the online course. Furthermore, this study aimed to confirm the feasibility and satisfaction of online courses on global health education at medical schools, as online courses are emerging as an alternative to in-person courses due to the spread of COVID-19. 


\section{Methods}

The global health education course was established in 2017 to help second-year students at Seoul National University College of Medicine understand the status of global health and medical care in a social and human context, and to examine the relationships among health, disease, and the disease behavior of patients, as well as various aspects of the relationship between life and health, by contemplating the human and sociological aspects of medicine.

The course deals with various topics related to global health, such as the introduction of global health, the global burden of disease, Millennium Development Goals, Sustainable Development Goals, neglected tropical diseases, global health and nutrition, maternal health, children's health, and global surgery. In 2019, the course was conducted in person for a total of 14 hours. In addition to theoretical lectures, various teaching methods were used, such as group discussions, presentations, special lectures by overseas and domestic experts, and talk shows. In 2020, the course was conducted online for a total of 11 hours, with similar subjects and teaching methods. The reason for the decrease in the course's operating time is that some lectures and team-based learning sessions were compressed due to the transition to online lectures. In 2019, a total of 157 students took lectures and exams, of whom 74 students responded to the survey for this course. In 2020, 146 students took the lectures and exams, and 73 of them responded to the survey. This study was approved by the Institutional Review Board (IRB) of Seoul National University Hospital (IRB approval no., E-2007-134-1143). The requirement for written informed consent from the students was waived due to the anonymous and retrospective nature of this study.

\section{Comparison of participation, satisfaction, and academic achievement of medical students}

The participation, satisfaction, and academic achievement levels of medical students in 2019 were compared with those who took the course in 2020.

\section{1) Participation}

The participation of medical students was compared between 2019 and 2020 using the attendance rate. In 2019, when the students entered the classroom, they signed the attendance sheet. In 2020, online course attendance was measured for prerecorded video lectures and live streaming online lectures using Zoom. For the prerecorded video lectures, attendance was defined as viewing at least $95 \%$ of a lecture. The Zoom live streaming online lectures were made available 15 minutes before the beginning of class. Students who entered the Zoom classroom within 5 minutes of the starting time and remained present for at least $95 \%$ of the classes were regarded as in attendance.

\section{2) Satisfaction}

Satisfaction with the course was analyzed through a survey in both 2019 and 2020. The survey consisted of four questions pertaining to students' overall satisfaction with lectures, the presentation of educational goals, the organic connection between lectures, and whether the length of lectures was appropriate. For the four questions, they rated their responses on a 5-point Likert scale, with options including "very unsatisfied," "unsatisfied," "neutral," "satisfied," to "very satisfied." In this study, the Cronbach's $\alpha$ coefficient, which indicates internal reliability, was 0.971 for overall lecture satisfaction, 0.963 for presentation of educational goals, 0.971 for organic connection between lectures, and 0.973 for whether the length of lectures appropriate. 


\section{3) Academic achievement}

The academic achievement of medical students was compared between 2019 and 2020 using their score on the written final examination, which evaluated students' knowledge of the content covered in the global health course over 2 days, in three ways: memorization, interpretation, and problem-solving. The 2019 written examination consisted of a total of 21 questions, including 20 five-option multiple-choice questions (1 point each) and one essay with a score of 5 points. The 2020 written examination consisted of 15 questions, including 14 five-option multiple choice questions (1 point each) and one essay with a score of 6 points. The total score was converted into a scale of 1-100 to compare academic achievement between 2019 and 2020. Students were deemed to have reached the minimum requirement when a $60 \%$ was attained, and as having achieved high performance when they received a score of $90 \%$ or more.

\section{Preferences of medical students for in- person or online courses}

We surveyed the medical students who attended the online course in 2020 regarding whether they preferred in-person or online courses, using ratings of "strongly preferred," "preferred," and "no difference." Similarly, students were asked about whether they preferred prerecorded lectures or live streaming online lectures, and they rated their preferences in the same way.

\section{Comparison of satisfaction and the ad- vantages and drawbacks of the online course}

The medical students who took the online course in 2020 were surveyed regarding their satisfaction with the online delivery of the course and the advantages and drawbacks of online delivery. Students were asked about their satisfaction with online delivery through four questions pertaining to total satisfaction, video quality, sound, and speed. The advantages of online lectures were investigated through five questions about the time, place, pacing, and order of lectures, as well as the ability to repeat lectures; and the drawbacks of online lectures were investigated through four questions regarding the lack of interaction with professors, the lack of interaction with other students, difficulty concentrating, and difficulty in self-directed learning. The medical students responded to these questions with options of "very unlikely," "unlikely," "neutral," "likely," and "very likely." Responses of "very likely" and "likely" were categorized as "agree," while those of "very unlikely," "unlikely," and "neutral" were categorized as "disagree."

\section{Data analysis}

The collected data were statistically analyzed using IBM SPSS for Windows ver. 25.0 (IBM Corp., Armonk, NY, USA). The medical students' average attendance rate, overall satisfaction with the lecture, and written test scores were compared and tested with the independent $t$-test. The percentages of students who achieved for high performance and the minimum requirement were compared in both years. The percentages of preferences regarding methods of course delivery and the satisfaction of the medical students who took the online course, as well as their perceived advantages and drawbacks, were also analyzed.

\section{Results}

\section{Comparison of participation}

In 2019, 157 second-year medical students took the global health course, and 146 students did so in 2020. 
The students' average attendance rate was $95.0 \%$ in 2019 and $95.1 \%$ in 2020 . There was no significant difference in the average attendance rate between the two groups (Table 1).

\section{Comparison of overall satisfaction with lectures}

No significant differences were found between the students who took the course in 2019 and those who took the course in 2020 in terms of overall satisfaction, the presentation of educational goals, the organic connection between lectures, and whether the number of lectures was appropriate (Table 2).

\section{Comparison of academic achievements}

The mean score on the written examination was $78.0 \pm 18.3$ in 2019 and 84.1 \pm 19.6 in 2020, reflecting a significant difference $(t=-2.8, p=0.005)$. The percentages of students who achieved the minimum requirement
(95.9\%) and high performance (55.5\%) in 2020 were numerically higher than those who did so in 2019 (93.6\% and $14.6 \%$, respectively) (Table 3 ).

\section{Preferences regarding lecture methods}

The medical students who took online lectures in 2020 stated that they preferred online lectures (74.0\%) over in-person lectures (16.4\%). Additionally, they preferred prerecorded video lectures (56.2\%) over live streaming online lectures (37.0\%) (Table 4).

\section{Students' responses regarding their sat- isfaction with online lectures, and their advantages and drawbacks}

The medical students who took the online lectures in 2020 were surveyed on their satisfaction with the online lectures and their advantages and drawbacks. The students' satisfaction with the speed of online lectures was the highest (87.6\%), followed by image quality

\begin{tabular}{|c|c|c|c|c|}
\hline & \multicolumn{2}{|c|}{ Year } & \multirow{2}{*}{$\mathrm{t}$-value } & \multirow{2}{*}{$p$-value } \\
\hline & $2019(n=157)$ & $2020(n=146)$ & & \\
\hline Attendance rate & $95.01 \pm 19.83$ & $95.14 \pm 19.20$ & -0.06 & 0.96 \\
\hline
\end{tabular}

Data are presented as mean \pm standard deviation, unless otherwise stated.

Table 2. Comparison of Overall Satisfaction with the Course between 2019 and 2020

\begin{tabular}{|c|c|c|c|c|}
\hline & \multicolumn{2}{|c|}{ Year } & \multirow{2}{*}{ t-value } & \multirow{2}{*}{ p-value } \\
\hline & 2019 & 2020 & & \\
\hline I am overall satisfied with this course & $4.23 \pm 0.94$ & $4.19 \pm 0.94$ & 0.20 & 0.85 \\
\hline The educational objectives of each lectures were clearly presented & $4.20 \pm 0.97$ & $4.32 \pm 0.89$ & -0.77 & 0.45 \\
\hline The lectures in this course are organically linked to each other & $4.25 \pm 0.97$ & $4.40 \pm 0.80$ & -1.01 & 0.32 \\
\hline The length of lectures was appropriate & $4.18 \pm 1.02$ & $4.40 \pm 0.80$ & 0.21 & 0.15 \\
\hline
\end{tabular}

Data are presented as mean \pm standard deviation, unless otherwise stated.

Table 3. Comparison of Academic Achievement between 2019 and 2020

\begin{tabular}{|c|c|c|c|c|}
\hline & \multicolumn{2}{|c|}{ Year } & \multirow{2}{*}{ t-value } & \multirow{2}{*}{ p-value } \\
\hline & 2019 & 2020 & & \\
\hline Mean score $\pm S D$ & $78.04 \pm 18.33$ & $84.18 \pm 19.63$ & -2.82 & 0.005 \\
\hline High performance $(\%)$ & 14.6 & 55.5 & & \\
\hline Minimum requirement $1 \% 1$ & 93.6 & 95.9 & & \\
\hline
\end{tabular}

SD: Standard deviation. 
Table 4. Medical Students' Preferences regarding Teaching Methods

\begin{tabular}{llr}
\hline \multicolumn{1}{c}{ Variable } & \multicolumn{1}{c}{ Type } & $\%$ \\
\hline Method of course delivery & Online course & 74.0 \\
& In-person course & 16.4 \\
& No difference & 9.6 \\
Method of online lectures & Pre-recorded videos & 56.2 \\
& Live streaming online lectures & 37.0 \\
Total & No difference & 6.8 \\
\hline
\end{tabular}

Table 5. Comparison of Medical Students' Satisfaction with Aspects of the Online Lectures and their Advantages and Drawbacks

\begin{tabular}{lcc}
\hline \multicolumn{1}{c}{ Variable } & Agree (\%) & Disagree (\%) \\
\hline Satisfaction with online lectures & & \\
Satisfied with the running pace of each of the online lectures & 87.6 & 11.0 \\
Satisfied with the visual quality of each of the online lectures & 84.9 & 13.7 \\
Satisfied with the sound of each of the online lectures & 79.5 & 17.8 \\
Overall satisfied with each of the online lectures & 79.4 & 19.2 \\
Advantages of online lectures & & \\
Classes can be taken at any time & 93.1 & 5.5 \\
Classes can be taken from anywhere & 93.1 & 5.5 \\
You can repeat the classes & 86.3 & 11.0 \\
Classes can be taken at one's own pace & 82.1 & 16.5 \\
$\quad$ Classes can be taken in any order & 76.7 & 21.9 \\
Drawbacks of online lectures & & \\
Lack of interaction with peer learners & 56.1 & 43.9 \\
Less concentration than in the classroom & 49.3 & 50.7 \\
Lack of interaction with professors & 45.2 & 53.4 \\
Difficulty maintaining consistent self-directed learning & 43.8 & 54.8 \\
\hline
\end{tabular}

(84.9\%), sound quality (79.5\%), and overall satisfaction (79.4\%). Regarding the advantages of online lectures, 93.1\% agreed that an advantage was the ability to take classes at any time and place, followed by the possibility to repeat lectures $(86.3 \%)$, the ability to take classes at the pace they wished $(82.1 \%)$, and the ability to take classes in the order they wanted (76.7\%). The drawbacks of online lectures were the lack of interaction between peer learners (56.1\%), while $49.3 \%$ cited decreased concentration compared to the classroom environment, 45.2\% stated that a disadvantage was the lack of interaction with professors, and $43.8 \%$ indicated that they difficulty consistently maintaining self-directed learning (Table 5).

\section{Discussion}

The scope of medical education must be established through discussions with specialized academic organizations, such as academic societies dedicated to medical education, and various stakeholders related to global health, innovate independently each medical school independently developing its related curriculum [9]. In response, the Seoul National University College of Medicine has been actively providing global health education courses to foster leadership and a global health perspective, with a special focus on achieving its educational purpose of training medical professionals who will contribute to humanity and society, based on 
the value of respect for human beings [3].

Due to the spread of COVID-19, Seoul National University College of Medicine actively used online learning methods. These online learning methods have been implemented in various countries over the past decades to provide new and effective medical education. Researchers at a medical school in Canada compared medical students' changes in knowledge and the feasibility and satisfaction of e-learning modules by randomly assigning students to either an e-learning group or a PDF article reading group to improve students' conceptual global health knowledge [6]. Another study confirmed the feasibility of online learning and evaluated intercultural peer learning through online collaborative group activities of medical students in Australia and Indonesia [10].

In our study, the participation, satisfaction, and academic achievement levels of medical students in the online global health education course had comparable results to the in-person education course. Another study referred to "ease of access" as a facilitator for e-learning $[6,7]$, as e-learning is free from time and space constraints; this has been cited as the most important advantage of online education [11]. Medical schools' curricula must deliver vast medical knowledge and skills within limited time, and the location of classes may vary between classrooms, medical practice rooms, and the hospital [11]. Regarding this issue, online classes can save time and are effective in terms of educational costs, as it is easy to secure online space for education [7].

Medical students who took the global health education in 2020 preferred online courses over in-person courses, due to the former's greater flexibility, the easily understandable content of classes with materials that could be repeated, and the possibility of self-directed learning and taking classes according to one's individual conditions and pace. Several studies support these findings [12,13]. Another study noted that students felt familiar with the use and accessibility of online education [14].

Among the online methods of course delivery, medical school students preferred video lectures over live streaming online lectures. This result is consistent with the intrinsic strengths of online lectures, which enable classes to be repeated at students' own pace. Lectures focusing on the delivery of global health knowledge could promptly communicate the content of the learning activities through prerecorded videos, thereby increasing satisfaction with the class in 2020. Small-group learning and question-and-answer sessions with experts were expected to increase the satisfaction of live streaming online lectures. We attempted to compensate for the lack of interaction with peer learners and between instructors and students through live streaming online lectures.

In a study of Hranstinski [15], the real-time video and sound of the lecture were combined to enable the students to feel as though they were taking the lecture in the classroom, which enhanced interactions through the effective exchange of information and opinions among participants. Live streaming online lectures foster an environment in which collaboration and cooperation can be effectively achieved for learners who require team-based learning [16].

Despite the advantages of online education, its most significant drawback in this study was found to be the lack of interaction with peer learners. Several other drawbacks were cited, such as individual environments where students experience greater difficulty concentrating than in a classroom, a lack of interaction with professors, and difficulty in maintaining self-directed learning. Online education allows students to acquire medical knowledge without time or space constraints. However, it has a limited ability to create and support an effective collaborative learning community with personal 
encounters, due to the lack of potential learning opportunities [10,17], and a sense of belonging, the defining characteristic of a learning community [18]. Considering that other shortcomings can be overcome with technical development, the way of adapting online education to foster community should be carefully considered as a direction for medical education in the post-COVID-19, to promote exchange among peer learners and a sense of learning community.

The limitations of this study are as follows. First, as this study targeted a specific grade level at one medical, the generalizability of the results of this study to all medical students is limited. Second, in comparing the written final exams score of 2019 and 2020, we were not able to conduct an analysis of the 2-year test items. Therefore, we should be careful to conclude that online education shows better results than in-person education in terms of academic achievement.

In conclusion, this study aimed to compare and analyze students' participation, satisfaction, and academic achievement in online and in-person global health education courses, and to determine the satisfaction and feasibility of the online course. The participation level in the online course showed similar participation rate to the in-person course. The online course also maintained the educational effects, both in terms of the percentage of students who achieved the minimum requirement and those who achieved high performance, compared to the in-person course. Students were shown to prefer online courses over in-person courses, as online courses can be more flexibly adapted to each learner's situation and learners can improve their understanding of each lecture's content through repetition. The greatest drawback of online lectures was found to be insufficient interaction with peer learners. This lack of interaction results in an absence of belonging, an important factor in fostering a learning community. Therefore, in online education, a broad range of methods and tools should be considered to promote interaction among peer learners to improve their sense of belonging to a learning community.

\section{ORCID:}

Su-Jin Lee: https://orcid.org/0000-0002-3142-8267;

Jayoung Park: https://orcid.org/0000-0003-2612-5509;

Yoon Jung Lee: https://orcid.org/0000-0002-4164-625X;

Sira Lee: https://orcid.org/0000-0001-8683-3932;

Woong-Han Kim: https://orcid.org/0000-0003-2837-7929; Hyun Bae Yoon: https://orcid.org/0000-0003-4367-5350

Acknowledgements: The authors would like to acknowledge the JW LEE Center for Global Medicine, Seoul National University School of Medicine, for ongoing support.

Funding: JW LEE Center for Global Medicine, Seoul National University School of Medicine funded the study.

Conflicts of interest: No potential conflict of interest relevant to this article was reported.

Author contributions: HBY conceived and designed the study. SJL and SRL analyzed and interpreted the data. SJL drafted the initial version of the manuscript. YJL, JYP, WHK, and HBY provided critical comments. All authors discussed and agreed on the data collection strategy.

\section{References}

1. Margolis CZ, Deckelbaum RJ, Henkin Y, Alkan M. Bringing global issues to medical teaching. Lancet. 2002;359(9313):1253-1254.

2. Frenk J, Chen L, Bhutta ZA, et al. Health professionals for a new century: transforming education to strengthen 
health systems in an interdependent world. Lancet. 2010;376(9756):1923-1958.

3. Seoul National University College of Medicine. Seoul National University College of Medicine brochure. https://medicine.snu.ac.kr/sites/medicine.snu.ac.kr/files/2 0180831\%20\%EC\%98\%81\%EB\%AC\%B8\%EB\%B8\%8C \%ЕВ\%AI\%9C\%ЕC\%8А\%88\%EC\%96\%B4_\%EC\%B5\%9 C\%EC\%A2\%85.pdf. Published August 2018. Accessed July 22, 2020.

4. Kim JW. Online education of Seoul National University College of Medicine. http://webzine.medicine.snu.ac.kr/ bbs/board/lists?bo_table $=202004 \& c a \_n a m e=\% E C \% 9 D$ \%98\%EB\%8C\%80\%EC\%86\%8C\%EC\%8B\%9D\#wr_id_ 8. Published April 2020. Accessed July 22, 2020.

5. Sandhu P, de Wolf M. The impact of COVID-19 on the undergraduate medical curriculum. Med Educ Online. 2020;25(1):1764740.

6. Gruner D, Pottie K, Archibald D, et al. Introducing global health into the undergraduate medical school curriculum using an e-learning program: a mixed method pilot study. BMC Med Educ. 2015;15:142.

7. Im EJ. Possibilities and limitations of e-learning in medical education. Korean Med Educ Rev. 2009;11(1): 21-33.

8. Cho KJ. An impact of peer learners' feedback (in reflection activity using SNS) on learners' academic self-efficacy, meta-cognition and learning achievement [dissertation]. Seoul, Korea: Ewha Womans University; 2015.

9. Bozorgmehr K, Saint VA, Tinnemann P. The 'global health' education framework: a conceptual guide for monitoring, evaluation and practice. Global Health. $2011 ; 7: 8$.
10. Ambrose M, Murray L, Handoyo NE, Tunggal D, Cooling N. Learning global health: a pilot study of an online collaborative intercultural peer group activity involving medical students in Australia and Indonesia. BMC Med Educ. 2017;17(1):10.

11. Macdonald C, Archibald D, Kellam H, Sun R, Stodel E, Puddester D. Evaluation of online health and wellness resources for healthcare professionals. Int J Adv Corp Learn. 201 1;4(2):18-23.

12. Noh SM. The effect of cyber class in medical education. Korean J Med Educ. 2002;14(1):61-71.

13. Park JH, Son JY, Yoo NJ, Kim S. A review on usage and effectiveness of e-learning in medical education. Korean J Med Educ. 2010;22(2):91-100.

14. Chumley-Jones HS, Dobbie A, Alford CL. Web-based learning: sound educational method or hype?: a review of the evaluation literature. Acad Med. 2002;77(10 Suppl): S86-S93.

15. Hrastinski S. Asynchronous and synchronous e-learning. Educ Q. 2008;31(4):51-55.

16. Strijbos JW, Martens RL, Jochems WM, Broers NJ. The effect of functional roles on perceived group efficiency during computer-supported collaborative learning: a matter of triangulation. Comput Human Behav. 2007; 23(1):353-380.

17. Arkorful V, Abaidoo N. The role of e-learning, advantages and disadvantages of its adoption in higher education. Int J Instr Technol Distance Learn. 2015; $12(1): 29-42$

18. Chang $\mathrm{H}$. The development of a learning community in an e-learning environment. Int J Pedagog Learn. 2012; 7(2):154-161. 